\title{
Short communication: Locus-specific interrelations between gene expression and DNA methylation patterns in bovine mammary gland infected by coagulase-positive and coagulase-negative staphylococci
}

\author{
T. Ząbek, ${ }^{1 *} \oplus$ E. Semik-Gurgul, ${ }^{1} \oplus$ K. Ropka-Molik, ${ }^{1} \oplus$ T. Szmatoła, ${ }^{1,2} \odot$ E. Kawecka-Grochocka, ${ }^{3} \oplus$ \\ M. Zalewska, ${ }^{3,4}$ (D) E. Kościuczuk, ${ }^{3}$ M. Wnuk, ${ }^{5}$ and E. Bagnicka ${ }^{3}$ (D) \\ ${ }^{1}$ National Research Institute of Animal Production, Krakowska 1, 32-083 Balice, Poland \\ ${ }^{2}$ University of Agriculture in Krakow, University Centre of Veterinary Medicine Krakow, Al. Mickiewicza 24/28, 30-059 Krakow, Poland \\ ${ }^{3}$ Institute of Genetics and Animal Breeding of the Polish Academy of Sciences, Postępu 36A, Jastrzębiec, 05-552 Magdalenka, Poland \\ ${ }^{4}$ Department of Applied Microbiology, Institute of Microbiology, Faculty of Biology, University of Warsaw, Miecznikowa 1, 02-096 Warsaw \\ ${ }^{5}$ Department of Biotechnology, University of Rzeszow, Pigonia 1, 35-310 Rzeszow, Poland
}

\begin{abstract}
Pathogens are able to alter the cell cycle program and immune response of the host by changing the transcription and epigenetics of genes responsible for cell cycle control and inflammation. In this regard, we evaluated interrelations between DNA methylation and expression of autophagy, apoptosis, and lipid metabolism-related genes in a sample set of mammary gland secretory tissue sections derived from bovine mammary glands infected with coagulase-negative and coagulase-positive staphylococci. We assessed relative transcript abundance and DNA bisulfite sequencing in loci of the ATG5, IGF1R, TERT, and DGAT1 genes. Lack of DNA methylation in ATG5 and DGAT1 loci might be associated with maintenance of ATG5 and DGAT1 expression regardless of the health status of bovine mammary gland. Complete methylation of intragenic $\mathrm{CpG}$ regions in the $I G F 1 R$ locus was apparently not related to the presence of its transcript in the investigated udder parenchyma samples. Detected hypermethylation of the TERT upstream element was associated with a small amount of TERT mRNA in bovine mammary gland, regardless of the presence, or absence, of the pathogen. A significant decrease in TERT gene expression in tissue sections of mammary gland free of bacteria and in those infected with coagulase-positive staphylococci was observed in parenchyma samples infected with coagulase-negative staphylococci. Two possible explanations are the direct involvement of the TERT gene in the etiology of bovine mastitis or the increase of TERT mRNA due to activation of the MAPK signaling pathway in response to release of exotoxins by coagulase-negative bacteria in the bovine mammary gland.
\end{abstract}

Received February 20, 2020.

Accepted June 25, 2020.

*Corresponding author: tomasz.zabek@izoo.krakow.pl
Key words: mastitis, DNA methylation, differential gene expression

\section{Short Communication}

Pathogens represent highly active environmental agents able to alter the host transcriptional program (Tran Van Nhieu and Arbibe, 2009). Staphylococcus aureus is one of the most frequently isolated pathogens in bovine mastitis and may cause a severe or chronic subclinical form of the disease. This coagulase-positive bacterium may lead to pathogenic induction of gene expression in infected cells of the host (Heimer et al., 2010). Moreover, pathogens may alter the epigenetic machinery of gene regulation (Tran Van Nhieu and Arbibe, 2009). Methylation is a chemical modification of DNA that can block gene activity. Methylation of regulatory sequences enriched in $\mathrm{CpG}$ sites is associated with compacted chromatin, an environment that impedes binding of transcriptional factors. In contrast, a lack of methylation of regulatory elements facilitates gene transcription (Deaton and Bird, 2011). Once inherited, DNA methylation patterns undergo changes throughout life under environmental influences and aging-relevant processes. As a result, alterations in methylation of regulatory sequences can indicate interactions between the environment and gene expression patterns.

With respect to mastitis-induced chronic inflammation of the mammary gland, in the current research we evaluated the importance of methylation and expression profiles of genes important for autophagy (ATG5; Ye et al., 2018), cell growth and apoptosis (IGF1R; Werner and Le Roith, 2000), and telomere functioning (TERT; Blackburn, 2005). In the current study, we also assessed the relevance of methylation or expression patterns of the DGAT1 gene in studied material, polymorphisms in which are crucial for milk fat composition (Grisart 
et al., 2004). In general, DGAT enzymes modulate the inflammatory effects of fatty acids in white adipose and muscle tissues (Yen et al., 2008; Koliwad et al., 2010). However, we wanted to determine whether links exist between DGAT1 activity and pathogen-induced inflammation related to mammary gland infection.

In this study, we evaluated RNA and DNA samples of parenchyma tissue of bovine mammary gland infected with coagulase-positive and coagulase-negative staphylococci and uninfected tissues. Inspected samples were previously tested against bacterial infection on the basis of microbiological examination. Detailed information on animals, their maintaining conditions, tissue sampling, and milk microbiological examination is presented in Kościuczuk et al. (2014, 2017). The experimental groups in the present report included 31 tissue sections obtained from 18 donor cows with confirmed infection with coagulase-positive staphylococci (CPS group) and 14 tissue sections infected with CNS obtained from 11 cows (CNS group; Supplemental Table S1; https://doi.org/10.3168/jds.2020-18404). The control group included 11 tissue sections free of bacteria obtained from 6 healthy cows (H group; Supplemental Table S1). Tissue sections came from different quarters of the udder, depending on the presence or lack of particular type of bacteria (as designated in the first column of Supplemental Table S1).

Total RNA of the parenchymal tissue samples was isolated using PureLink RNA Mini Kit (Applied Biosystems/ThermoFisher Scientific, Waltham, MA) including an RNA purification stage using PureLink DNase Set (Applied Biosystems/ThermoFisher Scientific). The quantity and quality of RNA were examined using a Nanodrop spectrophotometer (Thermo Scientific, Warsaw, Poland) and 2\% gel electrophoresis. Reverse transcription was performed on $500 \mathrm{ng}$ of total RNA using High-Capacity cDNA Reverse Transcription Kit (Applied Biosystems/ThermoFisher Scientific) according to the manufacturer's protocol. Reverse transcription (RT)-PCR primers were designed with the option to span at least one intron or to cover exon junctions using Primer-BLAST software (https://www.ncbi.nlm .nih.gov/tools/primer-blast/index.cgi; Supplemental Table S2; https://doi.org/10.3168/jds.2020-18404). Qualitative RT-PCR was performed for the pool of 11 equimolar cDNA samples including 4 CPS $(750 \mathrm{PP}$, 782LT, 842PP, 855PP), 4 CNS (662LP, 750LT, 829PP, 857LT), and free $\mathrm{H}$ samples (719P, 749LT, 861LP; Supplemental Table S1), with the use of Hotstart Taq DNA polymerase (Qiagen, Hilden, Germany) and 35 cycles of amplification. Obtained PCR amplicons were visualized after electrophoresis in $3 \%$ agarose gel stained with ethidium bromide. Quantitative RT-PCR reactions were run on QuantStudio 7 Flex System (Applied Biosystems/ThermoFisher Scientific) in 45 cycles, performed in triplicate for each cDNA sample. Reactions were in a total volume of $10 \mu \mathrm{L}$ using RTPCR primers and Sensitive RT HS-PCR Mix EvaGreen (A\&A Biotechnology, Gdynia, Poland). Quantification of mRNA levels was done using the comparative $\Delta \Delta^{\mathrm{CT}}$ method according to Pfaffl (2001), including relative mRNA abundance of $A C T B$ and RPS15 as endogenous controls (Bionaz and Loor, 2007). Normality of the distribution was tested using the Shapiro-Wilk test, and differences (in relative quantification values) between the CPS, CNS, and $\mathrm{H}$ groups of samples were calculated using the Mann Whitney U-test (results included in Table 1). Differences in expression were shown in boxplots.

Prepared DNA (Sherlock A\&A Biotechnology, Gdynia, Poland) was bisulfite converted (EpiTect Bisulfite Kit, Qiagen) and PCR amplified using bisulfite primers designed for converted DNA sequences in $\mathrm{CpG}$ islands (CGI) located upstream of the ATG5, DGAT1, and TERT genes, and inside the $I G F 1 R$ gene sequence (Supplemental Table S2; https://doi.org/10.3168/ jds.2020-18404). The CpG islands were defined using EMBOSS CpG Plot software (https://www.ebi.ac.uk/ Tools/seqstats/emboss_cpgplot/). Bisulfite (BS)PCR amplification was done with the use of Hotstart Taq DNA polymerase (Qiagen). The 2-stage protocol for BSPCR amplification (Supplemental Table S3; https:/

Table 1. $P$-values of fold change of expression differences between coagulase-positive staphylococci (CPS), CNS, combined CPS and CNS, and healthy $(\mathrm{H})$ sample group ${ }^{1}$

\begin{tabular}{lcccccc}
\hline \multirow{2}{*}{$\begin{array}{l}\text { Group x versus } \\
\text { group y }\end{array}$} & \multicolumn{3}{c}{ Fold change of expression differences } & & PM value differences \\
\cline { 2 - 4 } & ATG5 & DGAT1 & IGF1R & TERT & & TERT \\
\hline CPS vs. CNS & 0.22 & 0.66 & 0.91 & $0.04^{*}$ & \\
CPS vs. H & $0.06 \dagger$ & 0.65 & 0.16 & 0.24 & \\
CNS vs. H & 0.73 & 0.66 & 0.41 & $0.02^{*}$ & & 0.16 \\
CPS + CNS vs. H & 0.12 & 0.91 & $0.09 \dagger$ & $0.09 \dagger$ & & 0.11 \\
\hline
\end{tabular}

${ }^{1}$ The last column shows $P$-values of methylation differences in the TERT locus (Mqant method). PM $=$ methylation percent.

$\dagger P<0.10$ and ${ }^{*} P<0.05$. 
/doi.org/10.3168/jds.2020-18404), included 5 cycles at $64^{\circ} \mathrm{C}$ and 35 cycles at $62^{\circ} \mathrm{C}$ using $A T G 5$ primers, and 5 cycles at $60^{\circ} \mathrm{C}$ and 35 cycles at $58^{\circ} \mathrm{C}$ using DGAT1, $I G F 1 R$, and TERT primers. The BSPCR products were sequenced using bisulfite primers. Sanger sequencing products were separated by capillary electrophoresis on an ABI3500 xl Genetic Analyzer (ThermoFisher Scientific). Partially methylated CpG sites of inspected DNA fragments (TERT locus) were quantified. The first approach included calculation of percent of methylation $(\mathbf{P M})$ values using the Mquant method (Leakey et al., 2008) based on Sanger sequencing reads of BSPCR. Normality of the distribution was tested using the Shapiro-Wilk test and the differences between PM values of the CPS, CNS, and $\mathrm{H}$ groups were calculated on the basis of the Mann-Whitney U test (results included in Table 1).

The second approach relied on bisulfite sequencing using a cloning procedure of amplified DNA after equimolar pooling of samples representing each investigated group. Thirty nanograms of bisulfite-converted
DNA from each of $18 \mathrm{CPS}, 12 \mathrm{CNS}$, and $10 \mathrm{H}$ samples were pooled (Supplemental Table S1; https://doi.org/ 10.3168/jds.2020-18404) and subjected to BSPCR amplification as described above in a $30-\mu \mathrm{L}$ reaction volume. Amplicons were purified using Minelute PCR purification kit (Qiagen) and cloned using TOPO TA Cloning kit for Sequencing under manufacturer recommendations (ThermoFisher Scientific). Picked bacterial colonies (45 CPS, $27 \mathrm{CNS}$, and $18 \mathrm{H}$ BSPCR colonies) were amplified with T3 and T7 universal primers, purified with ExoSaP IT (ThermoFisher Scientific), and sequenced using the Sanger method. Quantification of $\mathrm{CpG}$ methylation and generation of methylation patterns based on clone BSPCR sequencing reads within each of investigated group were done using BISMA software (Rohde et al., 2010). Results are included in Table 2.

The relative quantification results did not reveal any significant differences in expression of DGAT1, ATG5, or IGF1R between the defined groups of udder secretory tissue samples (Figure 1). The Sanger bisulfite

Table 2. DNA methylation percent (PM) in TERT locus (gene ID: 518884) using the coagulase-positive staphylococci (CPS), CNS, and healthy (H) DNA bisulfite pooling approach for cloned bisulfite PCR sequencing ${ }^{1}$

\begin{tabular}{|c|c|c|c|c|}
\hline \multirow[b]{2}{*}{ CpG site } & \multirow[b]{2}{*}{ Distance to TSS } & \multicolumn{3}{|c|}{$\mathrm{PM}$} \\
\hline & & CPS & CNS & $\mathrm{H}$ \\
\hline CpG 1 & $-785 \mathrm{bp}$ to TSS & 48.80 & 63.00 & 31.20 \\
\hline CpG 2 & $-769 \mathrm{bp}$ to TSS & 77.30 & 85.20 & 68.80 \\
\hline CpG 3 & $-710 \mathrm{bp}$ to TSS & 77.30 & 85.20 & 75.00 \\
\hline CpG 4 & $-692 \mathrm{bp}$ to TSS & 86.40 & 92.60 & 50.00 \\
\hline CpG 5 & $-682 \mathrm{bp}$ to TSS & 95.50 & 70.40 & 75.00 \\
\hline CpG 6 & $-641 \mathrm{bp}$ to TSS & 88.60 & 96.30 & 87.50 \\
\hline CpG 7 & $-621 \mathrm{bp}$ to TSS & 63.60 & 29.60 & 93.80 \\
\hline CpG 8 & $-617 \mathrm{bp}$ to TSS & 75.00 & 85.20 & 100.00 \\
\hline CpG 9 & $-607 \mathrm{bp}$ to TSS & 100.00 & 100.00 & 87.50 \\
\hline CpG 10 & $-603 \mathrm{bp}$ to TSS & 97.70 & 88.90 & 87.50 \\
\hline CpG 11 & $-596 \mathrm{bp}$ to TSS & 93.20 & 88.90 & 68.80 \\
\hline CpG 12 & $-586 \mathrm{bp}$ to TSS & 86.00 & 92.60 & 81.20 \\
\hline CpG 13 & $-582 \mathrm{bp}$ to TSS & 95.50 & 81.50 & 100.00 \\
\hline CpG 14 & $-575 \mathrm{bp}$ to TSS & 81.80 & 88.90 & 93.80 \\
\hline CpG 15 & $-561 \mathrm{bp}$ to TSS & 86.40 & 66.70 & 75.00 \\
\hline CpG 16 & $-551 \mathrm{bp}$ to TSS & 75.00 & 92.60 & 87.50 \\
\hline CpG 17 & $-547 \mathrm{bp}$ to TSS & 93.20 & 100.00 & 100.00 \\
\hline CpG 18 & $-544 \mathrm{bp}$ to TSS & 93.20 & 88.90 & 100.00 \\
\hline CpG 19 & $-540 \mathrm{bp}$ to TSS & 93.20 & 96.30 & 87.50 \\
\hline CpG 20 & $-536 \mathrm{bp}$ to TSS & 70.50 & 77.80 & 62.50 \\
\hline CpG 21 & $-534 \mathrm{bp}$ to TSS & 59.10 & 63.00 & 31.20 \\
\hline CpG 22 & $-531 \mathrm{bp}$ to TSS & 88.60 & 74.10 & 68.80 \\
\hline CpG 23 & $-505 \mathrm{bp}$ to TSS & 88.60 & 100.00 & 62.50 \\
\hline CpG 24 & $-496 \mathrm{bp}$ to TSS & 47.60 & 59.30 & 31.20 \\
\hline CpG 25 & $-482 \mathrm{bp}$ to TSS & 75.00 & 77.80 & 75.00 \\
\hline CpG 26 & $-459 \mathrm{bp}$ to TSS & 56.80 & 51.90 & 62.50 \\
\hline CpG 27 & $-447 \mathrm{bp}$ to TSS & 70.50 & 63.00 & 43.80 \\
\hline CpG 28 & $-427 \mathrm{bp}$ to TSS & 90.90 & 85.20 & 100.00 \\
\hline CpG 29 & $-409 \mathrm{bp}$ to TSS & 59.10 & 81.50 & 75.00 \\
\hline CpG 30 & $-368 \mathrm{bp}$ to TSS & 44.20 & 29.60 & 50.00 \\
\hline CpG 31 & $-361 \mathrm{bp}$ to TSS & 50.00 & 51.90 & 37.50 \\
\hline \multirow[t]{2}{*}{ CpG 32} & $-350 \mathrm{bp}$ to TSS & 95.50 & 96.30 & 100.00 \\
\hline & Average PM for CGI & 78.25 & 78.26 & 73.44 \\
\hline
\end{tabular}

${ }^{1} \mathrm{TSS}=$ transcriptional start site; CGI $=$ CpG islands. 
ATG5

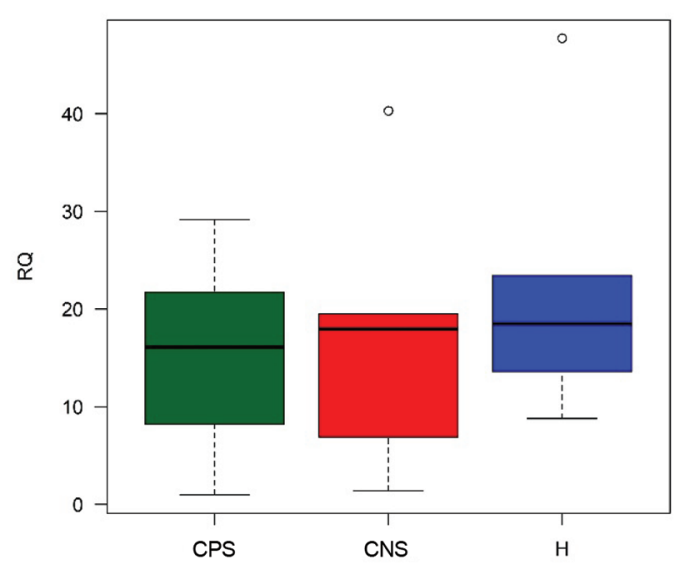

DGAT1

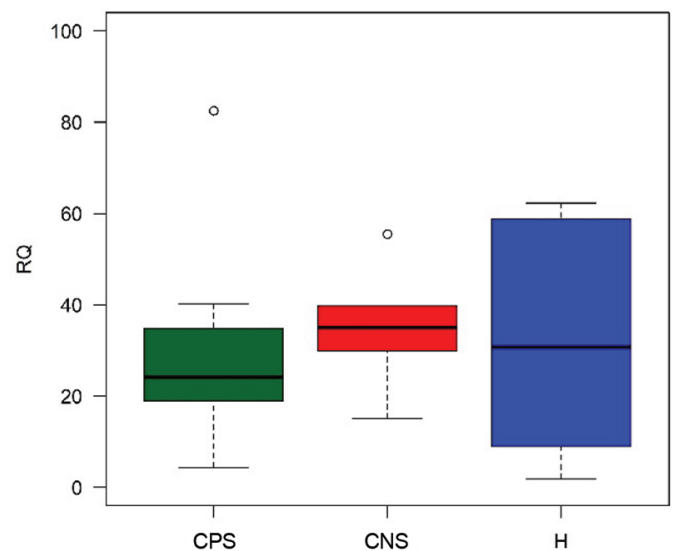

IGF1R

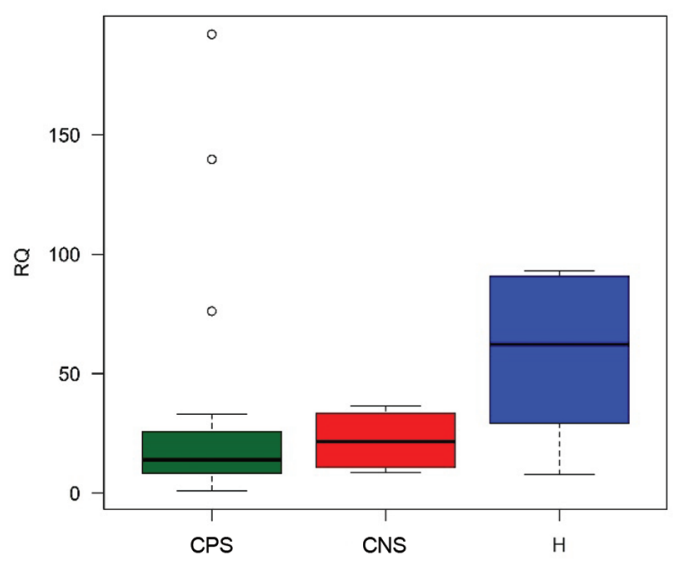

TERT

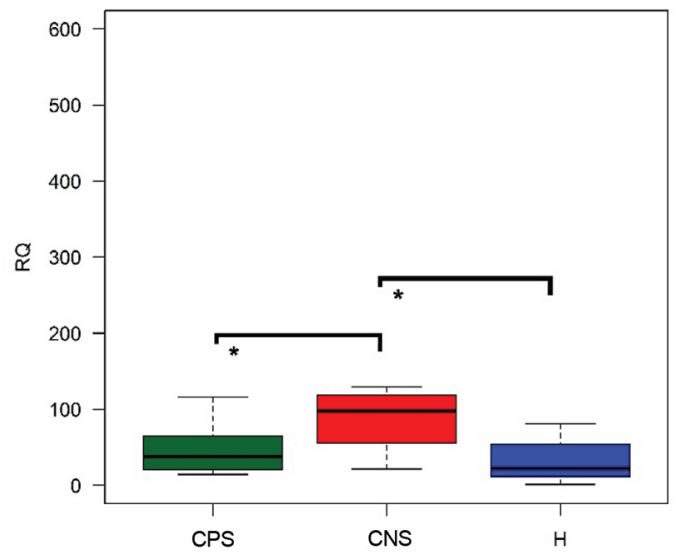

Figure 1. Box-and-whisker plots of differences in the expression of ATG5, DGAT1, IGF1R, and TERT genes among parenchymal tissue samples infected with coagulase-positive staphylococci (CPS) and CNS, as well as a healthy (H) sample group. The box represents 25 to $75 \%$ of the data, whereas the black line represents the median. Whiskers represent from 9 to $91 \%$ of the data and circles represent outliers. RQ $=$ relative quantity. Asterisk denotes a significant difference $(P<0.05)$ between CPS, CNS, and $\mathrm{H}$ groups.

sequencing of these genes showed a simple pattern of either hypo- (DGAT1 and ATG5) or hypermethylation $(I G F 1 R)$ of CGI in all parenchyma samples (examples shown in Supplemental Figures S1 to S3; https://doi .org/10.3168/jds.2020-18404).

The presence of clear RT-PCR product of DGAT1 of pooled cDNA samples of secretory tissue (Figure 2) was concordant with the lack of methylation of the DGAT1 upstream DNA sequence (Figure S1). Unaltered hypomethylation in DGAT1 might be associated with constant transcription of this gene, which has an embryonic background. The DGAT1 gene is crucial for mammary gland development, as found in model organisms, and its transcriptional activity is further maintained in the ontogeny, similarly to somatic tissues (Cases et al., 2004).
The hypomethylated state of the ATG5 upstream element (Supplemental Figure S2) coincided with the lowest amount of ATG5 transcript (Figure 2) compared with the other genes, probably because the investigated tissue sections came from lactating cows (Kościuczuk et al., 2014, 2017). Zielniok et al. (2017) reported higher expression of ATG5 in the dry period due to the autophagy required for regeneration of mammary glandular tissue.

Complete methylation of the investigated element of bovine IGF1R (Supplemental Figure S3) located in the intronic sequence did not correspond to the presence of clear PCR product of IGF1R of pooled cDNA samples of mammary gland (Figure 2). In this case, the inspected DNA sequence might not be functionally relevant for the regulation of $I G F 1 R$ expression, being 


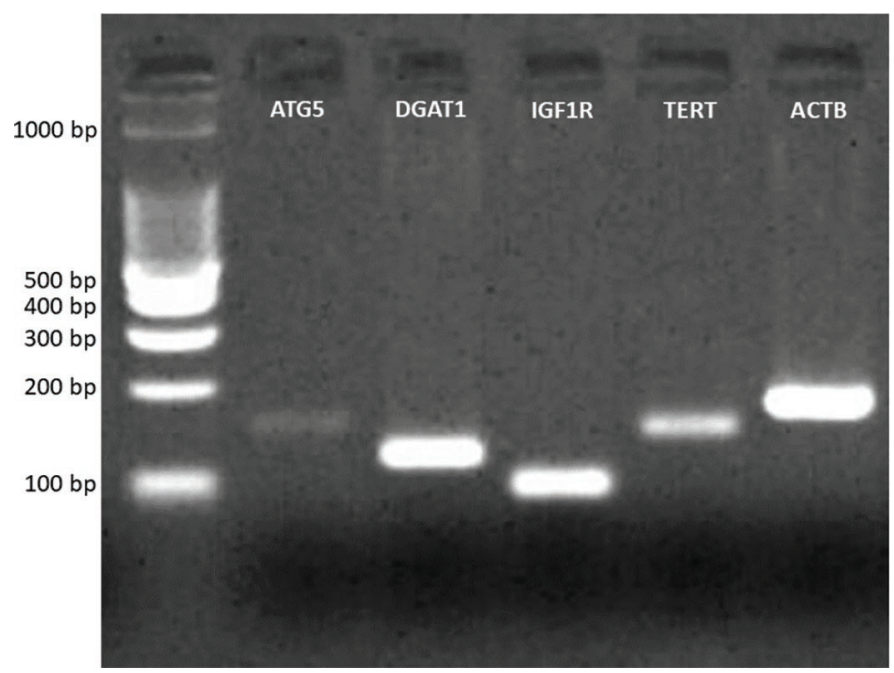

Figure 2. Qualitative reverse transcription-PCR results of pooled cDNAs of mammary gland secretory tissue samples. Lane 1 shows a 100-bp DNA ladder; lanes 2 to 6 show amplification products with the use of primers specific to ATG5, DGAT1, IGF1R, TERT, and ACTB mRNA (used as endogenous control for relative quantification).

fully methylated like most other DNA regions in mammalian genomes (Deaton and Bird, 2011).

The hypermethylation of CGI ( $>70 \%$ of methylation) of the upstream element of TERT gene in single and pooled DNA samples of parenchyma tissue (Figure 3 and Supplemental Figure S4; https://doi.org/10 .3168/jds.2020-18404) might be linked to low transcript abundance of TERT. This could be observed in the form of the weaker amplification product of pooled $\mathrm{cD}$ -
NAs compared with results of qualitative RT-PCR for $D G A T 1, I G F 1 R$, and $A C T B$ (Figure 2). A small amount of TERT mRNA has been reported in the majority of noncancerous somatic tissues (Kim et al., 1994). However, the results of quantitative RT-PCR showed a significant increase in expression of TERT in CNS samples compared with CPS samples $(P=0.04)$ and $\mathrm{H}$ samples $(P=0.02$; Figure 1$)$. Direct BSPCR sequencing and clone BSPCR sequencing results of the TERT upstream element did not show substantial differences between PM values of the CNS, CPS, and $\mathrm{H}$ groups of parenchyma samples (Figure 4). It is interesting that a whole-genome differential methylation study using methylated DNA immunoprecipitation (MeDIP-chip) microarray of mononuclear lymphocytes (PBMC) of Staph. aureus-infected cows revealed significant differential methylation of the bovine TERT locus between Staph. aureus-infected and control groups of animals, albeit with no difference in TERT mRNA abundance (Song et al., 2016). The mentioned MeDIP-chip enriched region encompassed an intragenic $\mathrm{CpG}$ site with a bivariate methylation state (Song et al., 2016). In our study hypermethylation of TERT upstream element detected in infected as well as noninfected samples does not correspond to significant TERT upregulation in CNS samples in comparison to CPS and $\mathrm{H}$ sample group.

The TERT gene encodes a telomerase responsible for the maintenance of chromosome ends (telomeres) in the majority of somatic cells. In the pathological state, telomere shortening is associated with cellular senescence,

\section{CPS}

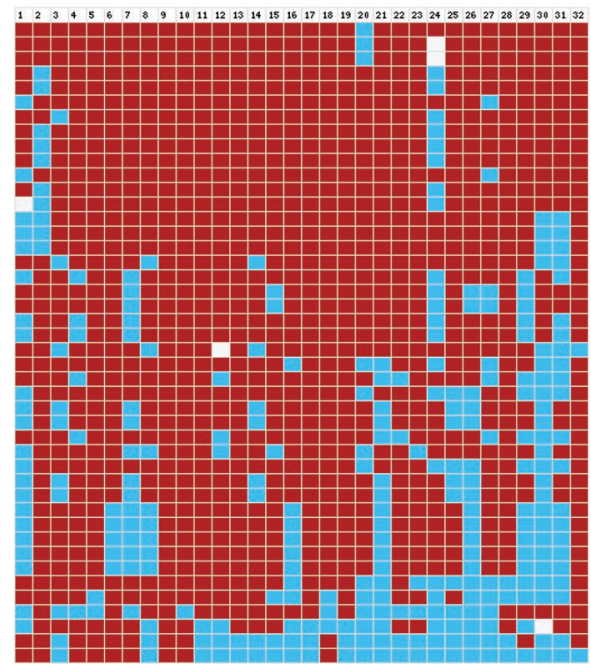

\section{CNS}

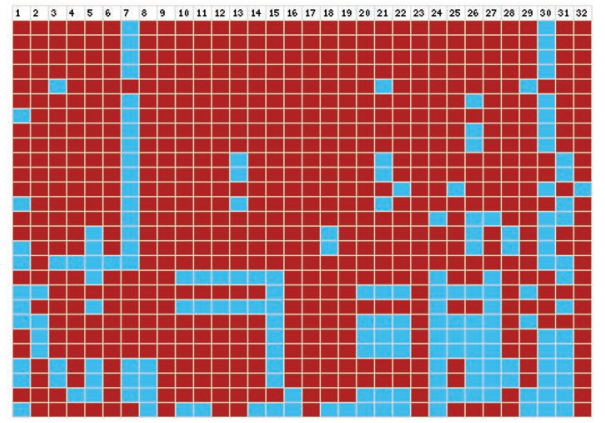

H

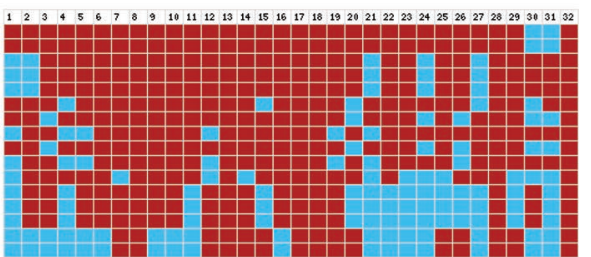

Figure 3. Methylation pattern at $32 \mathrm{CpG}$ sites of upstream element of TERT for coagulase-positive staphylococci (CPS), CNS, and healthy (H) group after Sanger sequencing of cloned bisulfite PCR (BSPCR) products of pooled DNA samples after conversion. Methylated cytosines are marked in red, whereas blue denotes lack of methylation in particular $\mathrm{CpG}$ position. White boxes denote lack of data due to sequencing or capillary electrophoresis difficulties. 
which manifests as chronic inflammation (caused by the impairment of immune cells) that is often observed in aged individuals (Shlush et al., 2011). Substantial telomere shortening is also associated with the occurrence of viral and bacterial infections, indicating that certain pathogenic microorganisms are able to alter the cell cycle process of the host (as reviewed by Kordinas et al., 2016). This phenomenon is usually associated with a decrease in telomerase activity (Kordinas et al., 2016). In the present report, we observed that the presence of coagulase-negative bacteria can induce TERT expression in host tissue. Based on previous articles, we hypothesize that the increase of telomerase activity caused by CNS in infected parenchyma samples might be induced by activation of genes of the MAPK signaling pathway in the cells of this secretory tissue. It is well known that Staph. aureus can increase mRNA expression of genes belonging to the MAP kinase pathway in epithelial cells due to the release of bacterial exotoxins (Heimer et al., 2010). It has been reported that TERT is one of the genes induced via MAPK signaling in a model of estradiol-treated human endometrial cancer cells (Zhou et al., 2013). Moreover, in previous transcriptomic studies related to CPS- and CNS-infected mammary glands, upregulation of particular loci of the MAPK signaling pathway was shown in udder secretory tissue infected with coagulase-negative $(F O S$ and EGR1 genes) and coagulase-positive bacteria (MAP3K; Kościuczuk et al., 2014, 2017). Interestingly, our results revealed that only the CNS group of bacteria could promote TERT expression in infected mammary gland. We confirmed that bacterial infection may modulate

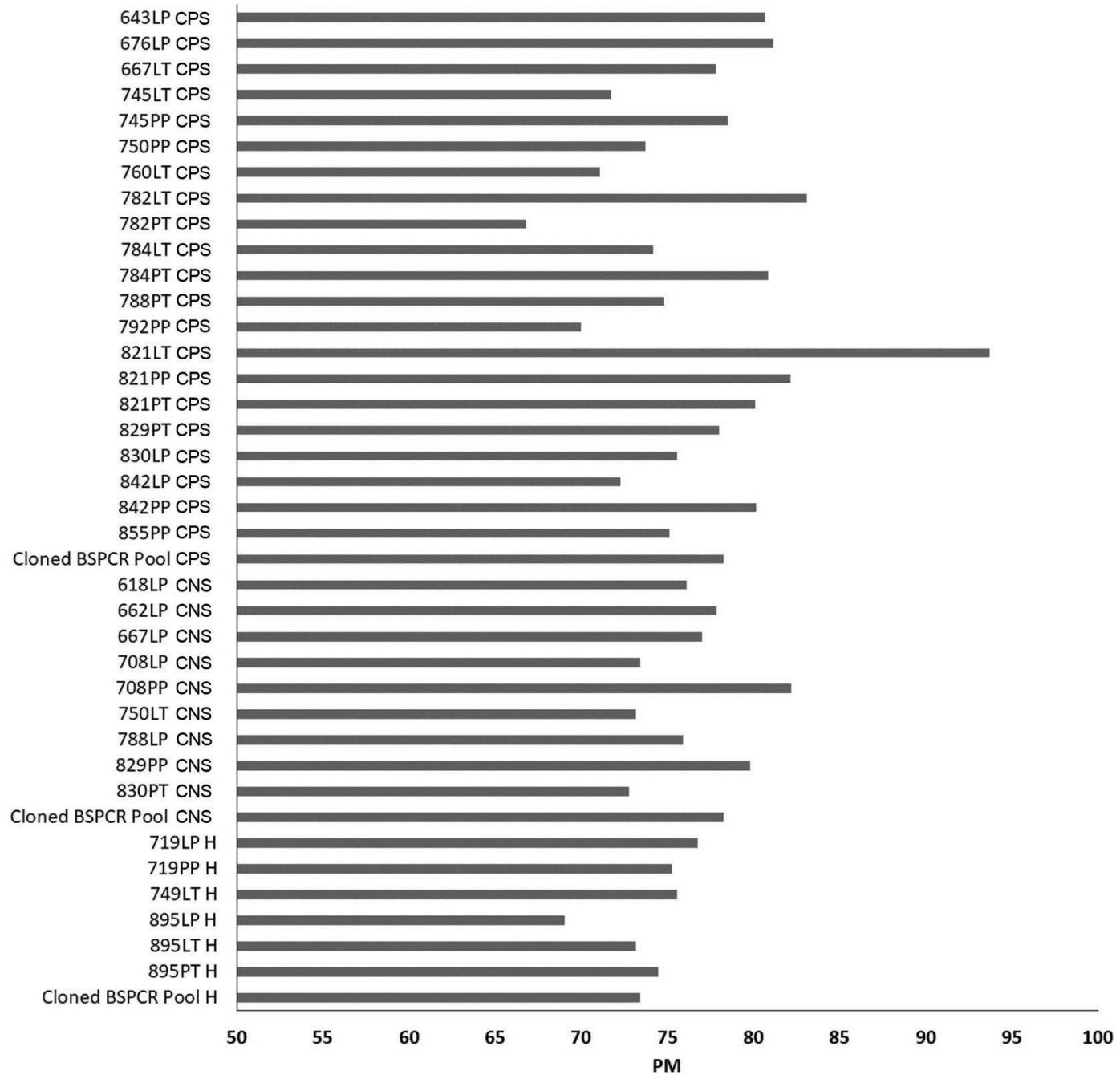

Figure 4. Average methylation percent (PM) across $32 \mathrm{CpG}$ sites of TERT upstream CpG islands (CGI) in sections of mammary gland infected with coagulase-positive staphylococci (CPS) and CNS, and in uninfected control samples (healthy, H). Visible variability of PM values of parenchyma samples does not indicate the presence or lack of bacteria; rather, it indicates the hypermethylation of the TERT upstream element. BSPCR = bisulfite PCR. 
telomerase activity during inflammation via changes in TERT expression (Kordinas et al., 2016).

We conclude that regulation of expression the ATG5, DGAT1, IGF1R, and TERT genes through DNA methylation during inflammation induced by bacterial infection of bovine mammary gland is negligible. The question remains as to whether significant alterations of gene expression of TERT are associated with the molecular mechanisms underlying the etiology of bovine mastitis or are a side-effect induced primarily by bacterial metabolites.

\section{ACKNOWLEDGMENTS}

The study was supported by the grant of The National Science Centre, Twardowskiego 16, Krakow, Poland, No. 2015/17/B/NZ9/01561. The authors have not stated any conflicts of interest.

\section{REFERENCES}

Bionaz, M., and J. J. Loor. 2007. Identification of reference genes for quantitative real-time $\mathrm{PCR}$ in the bovine mammary gland during the lactation cycle. Physiol. Genomics 29:312-319. https://doi .org/10.1152/physiolgenomics.00223.2006.

Blackburn, E. H. 2005. Telomeres and telomerase: Their mechanisms of action and the effects of altering their functions. FEBS Lett. 579:859-862. https://doi.org/10.1016/j.febslet.2004.11.036.

Cases, S., P. Zhou, J. M. Shillingford, B. S. Wiseman, J. D. Fish, C. S. Angle, L. Hennighausen, Z. Werb, and R. V. Jr. Farese. 2004. Development of the mammary gland requires DGAT1 expression in stromal and epithelial tissues. Development 131:3047-3055. https: //doi.org/10.1242/dev.01158.

Deaton, A. M., and A. Bird. 2011. CpG islands and the regulation of transcription. Genes Dev. 25:1010-1022. https://doi.org/10.1101/ gad.2037511.

Grisart, B., F. Farnir, L. Karim, N. Cambisano, J. J. Kim, A. Kvasz, M. Mni, P. Simon, J. M. Frère, W. Coppieters, and M. Georges, 2004. Genetic and functional confirmation of the causality of the DGAT1 K232A quantitative trait nucleotide in affecting milk yield and composition. Proc. Natl. Acad. Sci. USA 101:2398-2403. https://doi.org/10.1073/pnas.0308518100.

Heimer, S. R., A. Yamada, H. Russell, and M. S. Gilmore. 2010. Response of corneal epithelial cells to Staphylococcus aureus. Virulence 1:223-235. https://doi.org/10.4161/viru.1.4.11466.

Kim, N. W., M. A. Piatyszek, K. R. Prowse, C. B. Harley, M. D. West, P. L. Ho, G. M. Coviello, W. E. Wright, S. L. Weinrich, and J. W. Shay. 1994. Specific association of human telomerase activity with immortal cells and cancer. Science 266:2011-2015. https:// doi.org/10.1126/science.7605428.

Koliwad, S. K., R. S. Streeper, M. Monetti, I. Cornelissen, L. Chan, K. Terayama, S. Naylor, M. Rao, B. Hubbard, and R. V. Farese Jr.. 2010. DGAT1-dependent triacylglycerol storage by macrophages protects mice from diet-induced insulin resistance and inflammation. J. Clin. Invest. 120:756-767. https://doi.org/10.1172/ JCI36066.

Kordinas, V., A. Ioannidis, and S. Chatzipanagiotou. 2016. The telomere/telomerase system in chronic inflammatory diseases. Cause or effect? Genes (Basel) 7:60. https://doi.org/10.3390/genes7090060.

Kościuczuk, E. M., P. Lisowski, J. Jarczak, J. Krzyżewski, L. Zwierzchowski, and E. Bagnicka. 2014. Expression patterns of $\beta$-defensin and cathelicidin genes in parenchyma of bovine mammary gland infected with coagulase-positive or coagulase-negative staphylococci. BMC Vet. Res. 10:246. https://doi.org/10.1186/s12917-014 -0246-z.

Kościuczuk, E. M., P. Lisowski, J. Jarczak, A. Majewska, M. Rzewuska, L. Zwierzchowski, and E. Bagnicka. 2017. Transcriptome profiling of staphylococci-infected cow mammary gland parenchyma. BMC Vet. Res. 13:161. https://doi.org/10.1186/s12917-017-1088 -2 .

Leakey, T. I., J. Zielinski, R. N. Siegfried, E. R. Siegel, C. Y. Fan, and C. A. Cooney. 2008. A simple algorithm for quantifying DNA methylation levels on multiple independent $\mathrm{CpG}$ sites in bisulfite genomic sequencing electropherograms. Nucleic Acids Res. 36:e64. https://doi.org/10.1093/nar/gkn210.

Pfaffl, M. W. 2001. A new mathematical model for relative quantification in real-time RT-PCR. Nucleic Acids Res. 29:45e. https://doi .org/10.1093/nar/29.9.e45.

Rohde, C., Y. Zhang, R. Reinhardt, and A. Jeltsch. 2010. BISMA-fast and accurate bisulfite sequencing data analysis of individual clones from unique and repetitive sequences. BMC Bioinformatics 11:230. https://doi.org/10.1186/1471-2105-11-230.

Shlush, L. I., K. L. Skorecki, S. Itzkovitz, S. Yehezkel, Y. Segev, H. Shachar, R. Berkovitz, Y. Adir, I. Vulto, P. M. Lansdorp, and S. Selig. 2011. Telomere elongation followed by telomere length reduction, in leukocytes from divers exposed to intense oxidative stress-Implications for tissue and organismal aging. Mech. Ageing Dev. 132:123-130. https://doi.org/10.1016/j.mad.2011.01.005.

Song, M., Y. He, H. Zhou, Y. Zhang, X. Li, and Y. Yu. 2016. Combined analysis of DNA methylome and transcriptome reveal novel candidate genes with susceptibility to bovine Staphylococcus aureus subclinical mastitis. Sci. Rep. 6:29390. https://doi.org/10 $.1038 /$ srep29390.

Tran Van Nhieu, G., and L. Arbibe. 2009. Genetic reprogramming of host cells by bacterial pathogens. F1000 Biol. Rep. 1:80.

Werner, H., and D. Le Roith. 2000. New concepts in regulation and function of the insulin-like growth factors: Implications for understanding normal growth and neoplasia. Cell. Mol. Life Sci. 57:932942. https://doi.org/10.1007/PL00000735.

Ye, X., X.-J. Zhou, and H. Zhang. 2018. Exploring the role of autophagy-related gene 5 (ATG5) yields important insights into autophagy in autoimmune/autoinflammatory diseases. Front. Immunol. 9:2334. https://doi.org/10.3389/fimmu.2018.02334.

Yen, C. L., S. J. Stone, S. Koliwad, C. Harris, and R. V. Farese Jr.. 2008. Thematic review series: Glycerolipids. DGAT enzymes and triacylglycerol biosynthesis. J. Lipid Res. 49:2283-2301. https:// doi.org/10.1194/jlr.R800018-JLR200.

Zhou, C., T. A. Steplowski, H. K. Dickens, K. M. Malloy, P. A. Gehrig, J. F. Boggess, and V. L. Bae-Jump. 2013. Estrogen induction of telomerase activity through regulation of the mitogen-activated protein kinase (MAPK) dependent pathway in human endometrial cancer cells. PLoS One 8:e55730. https://doi.org/10.1371/journal .pone.0055730.

Zielniok, K., A. Sobolewska, and M. Gajewska. 2017. Mechanisms of autophagy induction by sex steroids in bovine mammary epithelial cells. J. Mol. Endocrinol. 59:29-48. https://doi.org/10.1530/JME $-16-0247$.

\section{ORCIDS}

T. Ząbek @i https://orcid.org/0000-0002-9795-3232

E. Semik-Gurgul ( https://orcid.org/0000-0003-4667-5495

K. Ropka-Molik @ (ㄴ https://orcid.org/0000-0002-8555-0495

T. Szmatoła @ https://orcid.org/0000-0003-1588-4198

E. Kawecka-Grochocka (® https://orcid.org/0000-0002-5339-3237

M. Zalewska @ https://orcid.org/0000-0001-5547-4607

M. Wnuk @ https://orcid.org/0000-0002-8518-6670

E. Bagnicka @ https://orcid.org/0000-0001-7193-2006 